
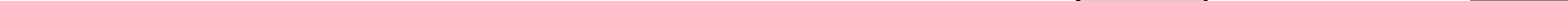


\title{
RECURSOS NARRATIVOS Y REPERCUSIONES FILOSÓFICAS: EL DOPPELGÄNGER EN LA LITERATURA DE IDEAS (GÓGOL, DOSTOIEVSKI Y KAFKA)
}

\section{NARRATIVE TECHNIQUE AND PHILOSOPHICAL CONSEQUENCES: THE DOPPELGÄNGER IN GÓGOL, DOSTOIEVSKI, AND KAFKA}

\author{
Leopoldo LA RUBia DE PRADO* \\ Universidad de Granada
}

\begin{abstract}
RESUMEN: Si hay algo que caracterizó a las Vanguardias artísticas fueron las nuevas sintaxis, los nuevos códigos expresivos a través de los cuales poder transmitir nuevos significados y avanzar en los procesos simbólicos y artísticos con objeto de profundizar en la exploración de la realidad a través del arte. Pero estos nuevos mecanismos tienen una raigambre, en ocasiones, muy anterior a la fecha de su popularización. Es el caso del Dopplegänger, del recurso del doble, que en el caso de Kafka sigue una línea clara cuyo origen se encuentra en el escritor ruso de origen ucraniano, N. V. Gógol y que sigue con F. M. Dostoievski. Las consecuencias de la utilización de este recurso son de una riqueza ontológica de primer orden.
\end{abstract}

* Trabajo realizado dentro del Grupo de Investigación denominado «Estudios de filosofía, retórica y estética» (HUM-192), financiado por la Consejería de Educación y Ciencia de la Junta de Andalucía, cuyo investigador principal es el Dr. José García Leal. El autor colabora también en el Proyecto de investigación del Ministerio, llamado «La filosofía como terapia social», cuyo investigador principal es el Dr. Luis Sáez Rueda. 
PALABRAS ClAVE: Dopplegänger, mecanismos narrativos, Kafka, Gógol, Dostoievski, burocracia y funcionarios.

ABSTRACT: If anything characterized the Avant-garde art was the new syntax, new expressive codes through which to convey new meanings and advance artistic and symbolic processes in order to deepen the exploration of reality through art. But these new mechanisms are rooted in some cases much earlier than the date of its popularity. Dopplegänger is the case, the use of the double, in the case of Kafka is a clear line that originated in the Russian writer of Ukrainian origin, $\mathrm{N}$. V. Gogol and continues with F. M. Dostoevsky. The consequences of using this resource are a first-order ontological richness.

KEYwORDS: Dopplegänger, narrative mechanisms, Kafka, Gogol, Dostoievski, bureaucracy.

\section{Introducción}

Del Romanticismo en adelante, los mecanismos narrativos (las nuevas sintaxis), — que tras el Impresionismo van a ser revolucionarias en las artes plásticas-, cobran una importancia de primer orden en la literatura y la poesía. Posteriormente, el primer tercio del siglo XX dio a luz no sólo a las llamadas Vanguardias artísticas, sino una honda preocupación por el modo de representación y sus más profundos condicionantes. Este viraje estético podría sintetizarse, entre otros modos así, en palabras del escritor polaco Bruno Schulz:

«Con el paso del tiempo, la palabra se endurece, coagula, deja de ser el conducto de nuevos significados. El poeta devuelve a las palabras su papel conductor a través de nuevos cortocircuitos que surgen de las acumulaciones» (328-329).

La sintaxis artística decimonónica y finisecular dejó de ser operativa, particularmente en las artes plásticas, se coaguló, y las Vanguardias, además de levantar acta de defunción de aquellos modos expresivos (o de la institución «arte», como es el caso del Dadaísmo) aportaron nuevos códigos provenientes del pasado más remoto, del primitivismo y el africanismo, entre otros, e incluso, en el 
caso de Picasso, de la cultura ibérica que tanto influyera en su obra a partir de 1907.

Pero, como he señalado, en la literatura estos cambios, en mi opinión, se producen con anterioridad a las artes plásticas. El Romanticismo y su vertiente más tenebrosa y siniestra, representada admirablemente por E.T.A. Hoffmann (17761822), Maupassant (1850-1893), Hawthorne (1804-1864), Poe (1809-1849), Stevenson (1850-1894), entre otros muchos, daría a luz mecanismos revolucionarios para la exploración de la conciencia y, en definitiva, de lo más íntimo del ser. Uno de estos mecanismos sería el Doppelgänger. Advirtamos por tanto, dos cosas: en primer lugar la importancia de los nuevos códigos expresivos que en el ansia de libertad creadora propia del Romanticismo florecen a partir, fundamentalmente, de esa época; y en segundo lugar, cómo los mecanismos narrativos (o sintácticos o expresivos) se constituyen en medios privilegiados en la exploración de la realidad.

El Doppelgänger, que es el mecanismo que nos ocupa en esta ocasión, es originalmente un vocablo alemán aplicado para el doble fantasmagórico de una persona viva. La palabra proviene de doppel, que significa «doble», "copia», «duplicado" y gänger, que podría ser traducida como «andante»; por tanto, sería algo así como el doble que camina (junto a ti). Su forma más antigua, acuñada por el novelista Jean Paul en 1796, es Doppeltgänger, «el que camina al lado». El término se utiliza para designar a cualquier doble de una persona, comúnmente en referencia al "gemelo malvado» o al fenómeno de la bilocación. También se utiliza la palabra para describir el fenómeno por el cual una persona puede ver su propia imagen por el rabillo del ojo. Los Doppelgänger aparecen en varias obras literarias de ciencia ficción y fantasía, en las cuales representan un tipo de metamorfo que imita a una persona o especie en particular por alguna razón, generalmente, nefasta. Cuando uno se encuentra ante este fenómeno (o una de sus variantes; no siempre se dan según la descripción basada en la etimología alemana) lo primero que siente es que "algo anda mal» en la narración, algo no cuadra, por decirlo así. Es el caso, por ejemplo de la magnífica película El otro, de Robert Mulligan. Uno está viendo a dos niños gemelos, rubitos, angelicales, pero no... ¡ $\mathrm{Nada}$ de eso! De la misma manera, cuando lees El doble de Dostoievski y aparece la figura del doble, semirreal, fantasmagórico, no se termina muy bien de ver qué está ocurriendo en la novela. Es preciso ser pacientes o, simplemente, saber que se trata de un Doppelgänger, es decir, de un doble irreal en un pla- 
no determinado, muy real a otro nivel. Como he señalado anteriormente, existen variantes del Doppelgänger y, en mi opinión, variantes extremadamente más complejas, como es el caso de Descripción de una lucha, de Franz Kafka, que abordaremos posteriormente.

\section{El Dopplegänger en Gógol, Dostoievski y Kafka}

Entre el escritor ruso de origen ucraniano Nikolái Vasílievich Gógol (18091852), el escritor ruso Fiódor Mijáilovich Dostoievski (1821-1881) y el escritor checo Franz Kafka (1883-1924), todos ellos eslavos, por tanto, existen numerosos nexos respecto a sus precupaciones filosóficas y existenciales, sus temáticas en torno a la figura de los funcionarios y la burocracia, sus inquietudes religiosas, su peculiar sentido del humor, etc, etc. No es motivo de este trabajo describirla de manera exhaustiva, pero en mi opinión existe una suerte de secuencia cinematográfica según la cual para entender adecuadamente distintas vertientes de la obra creativa de Kafka es preciso remontarse a Dostoievski, y de la misma manera, para entender determinadas cuestiones en Dostoievski es preciso partir de Gógol (Pobres gentes de Dotoievski es profundamente gogoliana, por ejemplo). De ahí que más allá de temáticas, preocupaciones y otras interesantes analogías, hayamos querido aquí completar de alguna manera estas semejanzas también en el terreno formal, a través del uso que todos ellos hacen de este mecanismo llamado Doppelgänger, que con sus variantes, todos ellos, con diferentes resultados, utilizan.

Las distintas obras sobre las que centraremos nuestra atención son:

- La nariz, de Gógol

- El doble, de Dostoievski

- Descripción de una lucha, de Kafka

«Entre nosotros, la categoría en el escalafón es lo primero que debe declararse», escribe Gógol en los primeros compases de El capote a propósito de los escalafones de la Administración Civil zarista, pues Akaki Akákievich, protagonista del relato, era «lo que se llama un perpetuo consejero titular, o sea, el núme- 
ro nueve entre las catorce categorías en que se divide el escalafón de nuestra Administración Civil». En 1722, en tiempos de Piotr I, fue publicada la «Lista de rangos ${ }^{1}$, uno de los documentos que determinaba tanto el sistema de rangos como el orden de la promoción en las carreras civil y militar. El ascenso a partir de este momento ya no dependía de la procedencia, sino de los méritos personales, así como de los años de servicio.

El capote nos muestra a un personaje de un patetismo sin límites, pero que ilusionado por un objeto, tras su sustracción, decide vengarse. La pérdida de la razón de Akaki revela la falsedad de una sociedad con profundas fallas en equilibrio inestable, con una base tan endeble como la sustentada en un sistema policial ineficaz y corrupto y en un modo de entender el mundo, como señalé al comienzo, donde "la categoría en el escalafón es lo primero que debe declararse»; una sociedad que en tales condiciones es caldo de cultivo de profundos cambios que, a la postre, tampoco daría los resultados esperados. Que sea desde ultratumba desde donde el fantasma de Akaki puede contribuir al equilibrio de una situación anómala muestra que, en realidad, para muchos no hay esperanza.

Al contrario que en El capote, en La nariz lo sobrenatural aparece desde el comienzo mismo del cuento. Una mañana, el barbero Iván Yákovlevich le comunica a su esposa, la respetabilísima Praskovya Osípovna que en lugar de tomar café prefiere comer pan caliente con cebolla. Nada más trivial. Iván Yákovlevich se dispuso a cortar el pan y «habiéndolo dividido en dos mitades, miró dentro y,

$\begin{array}{ll}1 \text { Rangos militares de tropas terrestres } & \text { Rangos civiles } \\ \text { Canciller } \\ \text { I. Mariscal de campo } & \text { Consejero secreto de número } \\ \text { II. General } & \text { Consejero secreto } \\ \text { III. Teniente general } & \text { Consejero de estado de número } \\ \text { IV. General mayor } & \text { Consejero de estado } \\ \text { V. Brigadier } & \text { Consejero colegiado } \\ \text { VI. Coronel } & \text { Consejero de la corte } \\ \text { VII. Teniente coronel } & \text { Asesor colegiado } \\ \text { VIII. Mayor (comandante) } & \text { Consejero titular } \\ \text { IX. Capitán } & \text { Secretario colegiado } \\ \text { X. Capitán ayudante } & \text { Secretario naval } \\ \text { XI. (NO EXISTE ESTA EQUIVALENCIA) } & \text { Secrario de distrito } \\ \text { XII. Teniente } & \text { Secretario provincial } \\ \text { XIII. Subteniente } & \text { Registrador colegiado } \\ \text { XIV. Alférez } & \end{array}$

Armada

Almirante general

Almirante

Vicealmirante

Almirante de retaguardia

Comandante capitán

Capitán primero

Capitán segundo

Teniente capitán

Capitán ayudante

Guardia marina

Guardia 
sorprendido, vio que algo brillaba allí. Iván Yákovlevich lo hurgó cuidadosamente con el cuchillo y lo tocó con el dedo. ¡Es duro! —se dijo—. ¿Qué podrá ser? Introdujo el dedo y sacó aquella cosa: ¡era una nariz! [...] Más aún, le parecía que era de algún conocido» (Gógol, 170). Iván Yákovlevich cayó presa del espanto, sin embargo aquello no era nada en comparación con la indignación mostrada por la respetabilísima Praskovya Osípovna que «golpeando antes de preguntar» le gritó a su marido «¿Dónde has cortado esa nariz, so animal? [...] ¡Canalla, borrachín! Yo misma te entrego a la policía» (170). Iván Yákovlevich sabía que aquella nariz no era sino la del asesor colegiado (octavo grado en la «Tabla de Categorías de la Administración Civil zarista) Kovalyov, a quien afeitaba los jueves y domingos. Con la crónica de estos hechos comienza Gógol un relato donde no hay verdadero asombro, sino una, en cierto modo, inquietante trivialidad.

En otro lugar, el asesor colegiado Kovalyov se despertaba bastante temprano, y queriendo examinar un granito que le había salido en la nariz el día anterior, pudo comprobar con asombro que donde debiera estar su nariz «lo que tenía era un espacio enteramente vacío y liso» (174). El asesor colegiado Kovalyov no tenía ya nariz. "Al momento mandó al criado que le ayudara a vestirse y corrió a ver al Jefe Superior de Policía» (174).

Es preciso señalar que Kovalyov hacía dos años que había recibido el título de asesor colegiado, pero "para ensalzar aún más su propia importancia y dignidad nunca se llamaba a sí mismo asesor colegiado, sino siempre comandante, o sea, la categoría correspondiente en el ejército» (174). El comandante Kovalyov fue a San Petersburgo, además de por necesidades económicas, para «buscar un cargo apropiado a su categoría; de tener suerte, sería vicegobernador, y de no tenerla, el de oficial administrativo en algún departamento importante. El comandante Kovalyov no mostraba inclinación a casarse, a menos que pudiera encontrar a una joven con doscientos mil rublos de dote» (175). Tales eran las pretensiones de Kovalyov: un importante cargo como funcionario y asegurarse una solvencia económica de acuerdo con sus aspiraciones en la administración. La pérdida de la nariz, lógicamente, lo complicaba todo.

Kovalyov sale a la calle envuelto en su capote con la cara cubierta, entra en una pastelería y cuando ve que no hay nadie mirándolo se acerca a un espejo y exclama colérico: «iSi por lo menos hubiera algo en la nariz..., pero no hay nada» (176). Sale de la confitería, y de repente queda petrificado, «estaba ocurriendo 
algo inexplicable; un carruaje se detuvo delante de la entrada, se abrió la portezuela del vehículo y un caballero vestido de uniforme bajó de un salto y, agachándose, subió corriendo la escalera. ¡Figúrense el horror de Kovalyov, a la vez que su asombro, cuando reconoció que aquello era su propia nariz!» (176). Kovalyov decide esperar el regreso del caballero. "Al cabo de un par de minutos salió efectivamente la nariz. Vestía de uniforme bordado de oro, con un gran cuello alto, pantalón de gamuza y espalda al flanco. Por su sombrero con plumas cabía deducir que era consejero de Estado, o sea funcionario de quinta categoría» (176). La nariz de Kovalyov había conseguido ese rango, mientras que el propio Kovalyov no era más que un asesor colegiado. Su nariz había llegado a ser lo que él no había podido conseguir. Kovalyov estaba fuera de sí e intenta hablar con el caballero, es decir, con su nariz, lo sigue hasta la catedral de Kazán y consigue hablar con él: «—Señor... — dijo Kovalyov, haciendo de tripas corazón—, señor...

— ¿Qué desea? — contestó la nariz, volviéndose a él. su sitio...

-Me resulta extraño, señor..., me parece... que debería usted saber cuál es

- Perdón, pero no entiendo a qué se refiere usted... Explíquese.

— ¿Cómo voy a explicarlo? — pensó Kovalyov, pero haciendo un esfuerzo dijo: - Claro que yo... ya ve usted... yo soy comandante, y reconocerá usted que no está bien que... un hombre de mi categoría ande por ahí sin nariz...[...] dad $[\ldots]$

—No comprendo ni jota — respondió la nariz—. Explíquese con más clari-

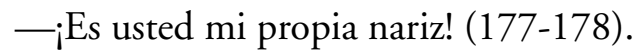

Nos encontramos, pues, ante una variante de Doppelgänger en este primer caso de la secuencia que comienza con este relato de Gógol, que proseguirá con El doble de Dostoievski y que culminará con Descripción de una lucha de Kafka. La nariz aparece, por tanto, en varios lugares al mismo tiempo: en el interior de una hogaza de pan y reencarnada en un consejero de Estado. No está donde debería de estar, ¿pero lo están estos funcionarios obsesionados por los ascensos y el prestigio social? En muchas de las obras de Gógol, pero también de otros autores eslavos, sus países están presentados en sus obras como países de funcionarios y burócratas. Funcionarios y burócratas que, en principio, deben de llevar a cabo una función de utilidad y servicio público que ni el mismo Max Weber y desde luego tampoco Nikolái Gógol criticarían en principio; sin embargo, Gógol sí lo hace porque este poder burocrático es un poder ajeno al pueblo y la buro- 
cracia rusa de la época, como la del Imperio Austro Húngaro de la que ya se ocupara el mismo Franz Kafka, Alfred Kubin o Robert Musil en El proceso o El castillo, La otra parte y El hombre sin atributos respectivamente. Estos funcionarios designados por el zar no cumplen con su deber, ni con él ni con el pueblo, como pone de manifiesto Gógol en su magnífica obra El inspector. La literatura de Gógol, apunta Siebers, engendra una nueva generación de monstruos fantásticos que, según parece, albergan la elevada ambición de ingresar en el servicio ruso $^{2}$. El asesor colegiado Kovalyov no lo consigue o al menos no en la medida en que soñaba. La frustración que generan unas expectativas tales son plasmadas en el relato a través de la creación de una forma de doble en la que la visión de su propia pérdida de la identidad que es ahora proyectada sobre su nariz, único órgano que tras abandonarlo llega a ser lo que Kovalyov no pudo, es la plasmación literaria de una consecuencia inevitable: la enajenación total o parcial de su propio yo. Esta es, en este caso, la función del Doppelgänger en el relato gogoliano.

La actualidad de este cuento, así como la de El doble de Dostoievski, en deuda con aquél y del cual nos ocuparemos a continuación, no puede ser mayor. Nuestra sociedad occidental genera una serie de expectativas en el marco de una movilidad social más nominal que real. El hombre moderno no puede escapar fácilmente a ellas, su entorno social y familiar tampoco, sin embargo, él lo intenta de algún modo, incluso con atajos, pero la consecución de éstos no siempre está al alcance de todos, lo cual genera un sentimiento de fracaso tanto para sí mismo como para el entorno social en el cual se mueve. El hombre se escinde entre lo que es y lo que hubiera querido ser sin poder salvar esa distancia que aumenta a medida que las posibilidades disminuyen. El hombre se cosifica hasta desaparecer como tal. El hombre ha vuelto a caer víctima de algo ajeno a él mismo al buscar fuera de sí lo que lo identificaría consigo mismo.

Finalmente, y tras ser rechazada su pretensión de poner un anuncio en el periódico a la espera de que alguien pudiera proporcionarle alguna pista para encontrar su nariz, Kovalyov se dirige al inspector de policía, hombre valiente y aficionadísimo al azúcar que hacía acopio en su comedor de este endulzante como resultado de su «amistad» con unos y otros comerciantes locales.

\footnotetext{
${ }^{2}$ Cfr. Tobin Siebers, p. 139.
} 
Que la policía encontrara su nariz (por casualidad, todo hay que decirlo) no soluciona, en resumidas cuentas, nada, puesto que ya no hay manera humana de poder volver a adherirla a su lugar de origen, salvo con soluciones chapuceras. Con ello la disociación en la personalidad de Kovalyov queda así consumada.

La mañana del siete de abril, como si nada hubiera pasado, Kovalyov pudo comprobar estupefacto y rebosante de alegría que su nariz se encontraba donde debía, o sea, entre las dos mejillas. La pesadilla había tocado a su fin. Ensayó varias estratagemas para corroborar que, efectivamente, su nariz seguía siéndolo. Todo volvía a la normalidad. El mismísimo Iván Yákovlevich acudió para cumplir sus funciones como barbero. Tras todas estas actividades, Kovalyov «se dirigió a la oficina del departamento en que estaba tratando de obtener el cargo de vicegobernador o, en caso de no lograrlo, de oficial administrativo» (Gógol, 201).

Como en El capote, en La nariz, Gógol describe no un mundo maravilloso, sino la vida de San Petersburgo en sus detalles más cotidianos; así, en El capote, Akaki es consejero titular, noveno en el escalafón. Akaki pierde la razón al mismo tiempo que la injusticia y la humillación hacen mella en él toda vez que pierde la ilusión de su vida: su nuevo capote.

En La nariz, Kovaliov es asesor colegiado, octavo en el escalafón. Kovaliov pierde la razón al ver a su propia nariz encarnada en un secretario de Estado.

Para muchos, la obra de Gógol es de una profunda crítica social, sin embargo, es mucho más que esto. En sus cuentos petersburgueses, funcionarios y artistas terminan todos perdiendo la razón y la ciudad de San Petersburgo es testigo de ello. Como cualquier otra gran ciudad, San Petersburgo ejerce un maléfico influjo sobre sus habitantes, pero Gógol, insisto, va mucho más allá. En su universo, como señala Nabókov, dos y dos son cinco, si no la raíz cuadrada de cinco, y en su obra, como en la de Kafka, todo ocurre con entera naturalidad. La cuestión del origen de los problemas sociales no es fácil de determinar, por eso autores como Gógol y Kafka dejan abierta a la interpretación su obra a través del recurso de la fantasía como modo de explorar la realidad. El realismo gogoliano, heredero del Romanticismo, hace uso de todos aquellos recursos que le son particularmente útiles para desenmascarar la realidad de su tiempo e indagar en la psique humana. Se establece así un nexo o una solución de continuidad entre el Romanticismo y esta forma de realismo (gogoliano), en las antípodas de la obso- 
leta idea de que los distintos movimientos artísticos se contraponen entre sí. La obra de Gógol no se puede encuadrar dentro de la literatura fantástica, sino que recurre a lo fantástico, como es el caso de Kafka, con otro objeto.

Como suele ocurrir en toda buena novela, el argumento de El doble se puede reducir a unas cuantas líneas, otras necesitan argumentos o tramas abstrusas con un decepcionante final que ocultan la falta de verdadero talento de un autor cuya penetración en la realidad adolece de los más básicos ingredientes al servicio de una narrativa ágil y sugerente.

El doble nos presenta el deterioro emocional progresivo de Yákov Petróvich Goliadkin, un funcionario con la baja categoría de Consejero titular, noveno en el rango civil, quien en su distanciamiento paulatino de la realidad que le circunda, que no de su propia realidad, llega a crear en su delirio una suerte de "yo ideal», de doble, un personaje semirreal con todas las características necesarias para triunfar allí donde el verdadero Goliadkin no lo consiguió. La deuda con Gógol está servida. Una imaginaria historia de amor con Klara Olsúfievna, hija única del Consejero civil, quinto en el escalafón civil Olsufi Ivánovich Berendéyev, sirve como pretexto para que el lector compruebe cómo Goliadkin va perdiendo el contacto con la realidad hasta terminar donde él sospechaba que terminaría, en un psiquiátrico.

En esta ocasión me voy a centrar en las causas y consecuencias del deterioro mental del protagonista dentro del contexto histórico, social y filosófico en que se desenvuelve.

Desde el comienzo de El doble, el protagonista, muestra claros síntomas de inseguridad y crisis de identidad: "¿Admito que soy yo o no? — pensaba nuestro héroe con indecible angustia- . ¿O finjo que no soy yo, sino alguien que se me parece, y hago como si nada hubiera pasado? En fin, que no soy yo, que sencillamente no soy yo, y basta (...) ¿Que no soy yo — murmuraba con esfuerzo-, que no soy yo, que no, señor, no soy yo, eso es todo!» (Dostoievski, 18-19).

La patología de Goliadkin no es óbice para poder comprobar su grado de inteligencia ni su integridad moral, en ese sentido, su distanciamiento de la rea- 
lidad atenta en gran medida contra ciertos criterios nunca definitivos de lo que se considera enfermedad mental, como puede ser el modelo estadístico, las expectativas sociales, el consenso u opinión de los expertos, el malestar subjetivo, la incapacidad social o laboral o una mala interpretación de la realidad. Pero Goliadkin le confiesa a su médico que simplemente él «sigue un camino distinto al de los demás», que «es un hombre de acción», que "gusta de la tranquilidad y no del trajín mundano», que es "un hombre sencillo y sin pretensiones al que no le seduce el brillo superficial» y que "está orgulloso de no ser un gran hombre y sí de serlo pequeño». Nadie podría objetar nada ante estas afirmaciones de Goliadkin. Se trata de un claro ejercicio de autoafirmación, aunque el mundo se desenvuelva por otros derroteros. Análogamente se expresaría uno de los mejores escritores del siglo XX, Robert Walser, quien despreciaba los ideales de prosperidad, aborrecía el éxito y era incapaz de someterse a ningún tipo de rutina o atadura.

Pero siguiendo con Goliadkin, éste muestra ya síntomas de un trastorno de índole paranoide, pues le pregunta a su médico que «cómo se vengaría de un enemigo, de su peor enemigo, o de quien juzgase usted como tal» (Dostoievski 26). «Tengo enemigos (...) tengo enemigos. Tengo enemigos mortales que han jurado destruirme» (27). Goliadkin, además, es rechazado en una fiesta a la que creía haber sido invitado, probablemente debido a su bajo rango de Consejero titular. Lo peor es que en esa fiesta se encuentra su amada Klara quien, obviamente, no le corresponde, con toda seguridad y entre otras cosas, porque ni siquiera sabe de su existencia. Dicho trastorno va quedando confirmado por sensaciones como que "le parecía que cuantos había en casa del anfitrión, Olsufi, le acechaban desde todas las ventanas. Sabía que si se volvía para mirarlos quedaría muerto en el acto» (41).

Dostoievski, en un capítulo profundamente irónico, como el IV, deja claras sus simpatías tanto por los funcionarios a los que denomina irónicamente «brillantes caballeros de la administración pública» como por Goliadkin al que llama «verdadero héroe de nuestra veraz historia» (47). Goliadkin pretende entrar a la fiesta de cumpleaños de Klara, pero el Consejero titular no logra sino quedarse en el descansillo de la escalera de servicio. La fiesta, una metáfora de hasta dónde se puede llegar en la vida si se es lo que se es, Consejero titular en el caso que nos ocupa, deja claro que desde el buffet, o sea, desde la entrada, hasta el salón donde se baila la polka, cada cual está donde puede, ya sea en el descansillo, como Goliadkin, ya sea en el salón de té, en el salón de juego o el paraíso 
— representado por el salón de baile— donde Klara, el amor o la felicidad se encuentran, eso sí, inaccesibles a aquellos que se encuentran en los rangos inferiores. Finalmente, Goliadkin hace de tripas corazón y logra introducirse, como quien no quiere la cosa, hasta el salón de baile, pero, como cabía esperar, todo sale mal y es expulsado de su propio sueño.

Esta situación traumática es la detonante de la «aparición» del doble de Goliadkin que no es otra cosa que la creación por parte de nuestro Consejero titular de un «yo ideal $»^{3}$ con las características necesarias para triunfar que su doble sí posee tan distantes de la personalidad de nuestro héroe, como lo son saber engatusar y camelarse a sus superiores, ganándose así su beneplácito, a través de engaños, con una sonrisa perenne, travieso, díscolo, pelotillero, deslenguado, sin talento, carácter, educación o sentimientos, etc, todas ellas características que le permiten triunfar en la buena sociedad, tan distantes de lo que caracteriza al propio Goliadkin, hombre sencillo y tranquilo que huye del oropel y aspira a vivir como simple ser humano. Su doble, un personaje semirreal fruto del delirio de Goliadkin, llega a convertirse en una pesadilla que aparece sentado sobre su cama, en la oficina, por la calle, en las fiestas... Y digo semirreal porque aunque no existe en la realidad (de los demás), sí que existe, y mucho, en la realidad de Goliadkin, lo cual nos llevaría a otra cuestión en torno al problema de la realidad como concepto subjetivo, vivencial. El Doppelgänger en el caso que nos ocupa es, por decirlo así, más canónico, se ajusta más a ese doble que camina junto a ti y que trae consigo malos presagios, ese gemelo mavado, ese duplicado que imita por alguna razón generalmente nefasta.

3 Quedarían vinculados pues los conceptos de Doppelgänger y el de «yo ideal»: El desarrollo de la confianza básica, es decir, confianza en sí mismo y en el resto, en un individuo normal está determinada por un ambiente que satisfaga las necesidades de cariño, cuidado, disciplina, estimulación, entre otros. Si no se satisfacen, el ambiente, en general, es percibido por el individuo como hostil acompañado con un sentimiento de frustración hacia sus necesidades lo que lo lleva hacia una separación de su yo real, según Karen Horney. Esto se produce porque el individuo, para compensar sentimientos de incompetencia y baja autoestima, crea un ideal muy alto y lo intenta alcanzar por medio de la fantasía, ya que en la realidad no es posible. Este fantasear se hace cada vez más continuo y vívido llegando a un momento en que su yo real es confundido y posteriormente reemplazado por su ideal planteado. De esta forma el individuo enajena su propio yo y su personalidad y asume sentimientos, pensamientos, motivos y acciones propios de su ideal configurándose así su yo ideal. Esta condición, que en un principio fue un conflicto entre necesidades contrarias es la que Horney denomina neurosis. 
Dostoievski, como Gógol o posteriormente Kafka, recurren a lo inconsciente, a lo fantástico y a determinadas técnicas narrativas para introducirse y explorar la realidad, recursos propios del Romanticismo. Esa escisión del protagonista de La nariz y de El doble no tienen apenas nada que ver con la esquizofrenia como patología (esto sería un recurso facilón y muy mañido, por cierto), aunque los resultados de la frustración en que se hallan tanto Kovaliov como Goliadkin, sobre todo este último, puedan conducirlo, finalmente, a un psiquiátrico. Son recursos literarios que tienen como objeto intensificar como, en principio, de ningún otro modo podría hacerse, la cuestión de mayor relevancia: la frustración y aunque pareciera contradictorio la esquizoidentidad del personaje en términos narrativos plasmada a través de un doble que consigue lo que en la realidad no se pudo. El Doppelgänger llega como recurso narrativo en Descripción de una lucha, de Kafka, a que nada más y nada menos que cuatro personajes sean, en realidad, el mismo.

Pero prosigamos con El doble. Tras un encuentro amistoso entre los dos goliadkines, el verdadero Goliadkin se vuelve a encontrar a su doble en la oficina, pero allí las cosas han dado un giro. El delirio del Consejero titular es irreversible. Se podría decir que para Goliadkin «todo estaba perdido» (105). Pero Goliadkin de repente, en tensión consigo mismo e intentando vencer a su nuevo enemigo, a su doble $\mathrm{y}^{4}$ teniendo en cuenta que todo se comienza a volver contra él, intenta salir adelante. Al comienzo del capítulo IX Dostoievski apela, como posteriormente el propio Kafka en numerosas ocasiones, a la teoría taoísta de «brazos caídos", popularizada por el propio Ghandi, también conocida como Laissez faire, que es una abreviación de la frase laissez faire, laissez passer, una expresión francesa que significa «dejad hacer, dejad pasar». Así, Goliadkin sentencia: «Venceré con la mansedumbre» (106). El delirio y el constante distanciamiento de la realidad continúa produciéndose de una manera cada vez más acentuada: Goliadkin pierde su trabajo, es abandonado por Petrushka, su criado, etc.

A Goliadkin le resta recurrir al Padre, no a su padre, sino al Padre, con mayúsculas, a Su Excelencia, que no es sino una metáfora de Dios Padre, en esa suerte de Olimpo representado por este relato de 1845 que es El doble, donde cada cual

${ }^{4} \mathrm{O}$ a sí mismo, en definitiva, o a una de sus vertientes, quizás denostada, pero en definitiva, en gran medida reconocida como modo de alcanzar lo que una parte de él desea, de ahí el «yo ideal» y el recurso al Doppelgänger. 
cumple una función y salvo algún que otro escribiente, ese hombre insignificante que es el Consejero titular Goliadkin representa, — de ahí que sea considerado por el propio Dostoievski como «nuestro héroe»-, al hombre de a pie sin otro patrimonio que el de la cordura, ahora perdida, la sencillez, el honor y la dignidad. Y no es casual que sea considerado «héroe», o mejor, antihéroe, como lo son numerosos protagonistas de la novela moderna, inmersos en un mundo absurdo e incomprensible, que surge de la desmitificación del héroe y de la falta de racionalidad del mundo, lo que los convierte en seres sin cualidades especiales, representantes de los mortales, de todos nosotros, porque Goliadkin es el único ser real de este relato, los demás son dioses y semidioses (de tres al cuarto, se podría decir) que concentran un cierto poder, dependiendo del lugar ocupado en el escalafón, seres irreales, como los dioses del Olimpo, que, sin embargo, marcan el camino a seguir y que como decía Epicuro en su defensa cuando fue acusado de ateo, pues claro que los dioses existen, están en el Olimpo, comen y beben y hablan griego (pero no se ocupan de los asuntos humanos). Tampoco a ese Olimpo de El doble le interesan los asuntos humanos. Y Goliadkin, ingenuo, recurre al Padre, porque si de Olimpo hablamos, Su Excelencia vendría a ser Zeus y se podría, desde luego, admitir una lectura religiosa de la obra. Pero el Padre al que recurre no lo reconoce (¿existe algo más trágico que tu propio padre o a quien consideras tu padre no te reconozca?). Goliadkin pretende que lo defienda, como haría cualquier padre, pero no lo defiende, Su Excelencia «le volvió la espalda» (171). Y es que Su Excelencia, General en el rango militar, Consejero secreto de número en el rango civil es el segundo en el escalafón, toda una deidad tan amada y anhelada como distante. De una hipotética, aunque justificada lectura religiosa de la obra se podría deducir — dadas las simpatías del autor con «nuestro héroe» y el tratamiento despectivo con ese Olimpo que representan los altos funcionarios- que si en alguna época Dostoievski tuvo dudas de tipo religioso es en este momento donde quedan plasmadas de manera meridianamente clara.

Olimpos análogos son los creados por el propio Franz Kafka en El Castillo y El proceso, ambas, creaciones épicas con dioses (Klamm, en El castillo, y el Alto Tribunal al que no había llegado jamás de El proceso) y semidioses y, cómo no, con el antihéroe como protagonista, un antihéroe con el rasgo estructural de poseer una «k» — como el propio autor- en su apellido, como el Agrimensor K, protagonista de El castillo, o Joseph K, protagonista de El proceso, de ahí, y por muchas razones más, Kafka se convierte en digno heredero de sus dos ilustres antecesores, Gógol y Dostoievski. 
Tanto en Gógol como en Dostoievski o en el propio Kafka (tanto en sus obras como, probablemente en ellos mismos) encontramos una característica común, propia también de la novela contemporánea: la búsqueda; una búsqueda que tiene como colofón la pérdida de la cordura, la frustración o la muerte sin haber conseguido por parte de los distintos protagonistas su anhelo del ansiado encuentro. ¿Búsqueda de qué o anhelo de qué? Buena pregunta. ¿De sí mismo, acaso?, ¿de Dios Padre? (cuando somos pequeños nuestro padre puede responder a muchas de nuestras preguntas, ¿pero y después?, ¿la ciencia?, puede, pero hay más preguntas, y la ciencia se ocupa únicamente de la realidad física, generalmente tangible o cuantificable, es decir, de una parcela muy restringida de la realidad); ¿búsqueda pues de sentido, de respuestas? ¡Dónde está nuestro padre/Padre cuando lo buscamos? ¿Nos podrá auxiliar? A Goliadkin no, a Josef K. tampoco.

Permítaseme ahora seguir buceando en las que yo considero alguna de las causas del deterioro emocional del funcionario Goliadkin a través de un análisis histórico y filosófico del asunto. Detengámonos, en primer lugar en la citada «Tabla de rangos»: "Con el fin de mejorar económica, técnica y socialmente el país, Pedro I —señala Isabel Martínez- abrió «una ventana a Europa» creando una nueva ciudad, San Petersburgo. Desde la sede de la nueva capital ya se podían apreciar rasgos específicos del futuro imperio ruso. Su estructura contaba con infinitas filas de burócratas, quienes formaban una sociedad compuesta íntegramente por funcionarios «chinóvniki». Los catorce grados o "chin» que los definían, correspondían al proyecto de la severa estratificación de la «Tabla de Rangos» petrovskiana. Con ésta, se sembraba en Rusia no sólo la creación de grados, distintivos, tratamientos, insignias y el correspondiente uniforme ${ }^{5}$ de funcionario, sino que a través de la «Tabla de Rangos», se transparentaba ya la construcción del gigantesco edificio burocrático del futuro sistema comunista en el que el uniforme y la clasificación de todos los miembros de la sociedad por grados y categorías cobrarían máxima importancia (...) El apoyo ofrecido por los occidentalistas a las «nuevas teorías» sociales fue consolidando el carácter burocrático de Rusia iniciado por Pedro I, y el diseño escalonado de la sociedad, promovido por el Zar, se extendió a todos los contextos vitales del hombre, repercutiendo su esencia jurídica en la sociedad en la religión, en la familia y en la moral» (Martínez, 30-31).

5 Una magnífica película —en realidad, una obra maestra - que ilustra esta cuestión es $E l$ último, dirigida por F.W. Murnau en 1924, protagonizada por el magnífico actor alemán Emil Jannings. 
El Zar deseaba alcanzar cultural y económicamente a Occidente, así que su objetivo consistía en reorganizar exhaustivamente el país. Él aplicó a su país - señala Isabel Martínez - rebuscados modelos occidentales, entre los que figuraba el del proyecto de funcionarización danés y prusiano. Prusiano, como Hegel.

El enfoque burocrático ha tenido sus grandes filósofos, sus grandes profetas y sus sociólogos célebres. Con toda probabilidad el mayor apologista filosófico del Estado fue Hegel, así como el mayor apologista sociológico del Estado fue Max Weber.

No cabe duda de que la vieja Prusia fue el paraíso de la burocracia y que, por consiguiente, no es algo puramente accidental el que los mayores apologistas del Estado y la burocracia procedieran de Prusia. De hecho, Hegel y Weber, cada cual a su manera y a niveles distintos de pensamiento teorético, son los metafísicos de la burocracia prusiana que generalizan partiendo de la experiencia de dicha burocracia prusiana y proyectan esa experiencia sobre la escena de la historia mundial. Por tanto, es necesario tener presente los postulados básicos de esta escuela de pensamiento. Para Hegel el Estado y la burocracia eran ambos el reflejo y la realidad de la idea moral, esto es, el reflejo y la realidad de la razón suprema, la realidad del Weltgeist, la manifestación de Dios en la historia: Max Weber, que en cierto modo es un descendiente de Hegel, incluyó la misma idea en el catálogo típicamente prusiano de las virtudes de la burocracia. De capital importancia es tener bien presente cuando el joven Hegel señala: «Porque todo Estado tiene que tratar a hombres libres como engranajes mecánicos...» (Eymar, 110).

Y con ello hemos llegado a la cuestión central: la tensión existente entre dos visiones contrapuestas del mundo, la hegeliana, la de los teóricos del Estado y de la burocracia como modo de administración del Estado como una de sus vertientes, y la visión sustentada por autores como el danés Søren Kierkegaard ${ }^{6}$ más tardíamente denominada Existencialismo, reivindicadora del hombre de carne y hueso, del hombre con nombre y apellido y no del hombre genérico, mera pieza de un engranaje mecánico que plantea la visión hegeliana. Pues bien, justo en medio de ambas visiones se encuentra el funcionario quien pretende afirmarse

\footnotetext{
${ }^{6}$ Junto al lado del mundo que representa Kierkegaard encontramos a D. Miguel de Unamuno, autor de El otro, una magnífica novela donde opera curiosamente este mecanismo que estamos analizando que es el Doppelgänger.
} 
como existente, pero negándose a través de las disfunciones que supone la institución burocrática. De ello se deriva lo que podríamos denominar condición esquizoide del hombre moderno. Y es que la burocracia no es un mal modelo administrativo, de ninguna manera, o mejor dicho, no tendría por qué serlo, pero a lo largo de su historia lo ha sido. La racionalidad implica adecuación de los medios a los fines. En el contexto burocrático, esto significa eficiencia. Una organización es racional si en ella se escogen los medios más eficientes para la implementación de las metas. Pero cuanto más racional y burocrática se vuelve una organización, tanto más los miembros individuales se convierten en engranajes de una máquina e ignoran el propósito y el significado de su comportamiento. La burocracia es una organización cuyas consecuencias deseadas se resumen en la previsión de su funcionamiento, con el propósito de obtener la mayor eficiencia de la organización. Al estudiar las consecuencias previstas de la burocracia, Merton notó las consecuencias imprevistas que la llevan a la ineficiencia y a las imperfecciones (lo que se denominó disfunciones de la burocracia).

El concepto popular de burocracia hace pensar que el grado de eficiencia administrativa de este sistema racional es muy bajo, puesto que el tipo ideal de burocracia sufre transformaciones en su acontecer. En la concepción mertoniana el hombre, cuando participa de la burocracia, hace que toda la previsión del comportamiento humano, escape al modelo preestablecido. Se verifican las disfunciones de la burocracia. Una disfunción es una consecuencia no prevista por el modelo weberiano.

Las disfunciones de la burocracia serían:

1. interiorización de las normas y exagerado apego a los reglamentos

2. exceso de formalismo y papeleo

3. resistencia al cambio

4. despersonalización de las relaciones

5. jerarquización como base del proceso de decisión

6. superconformidad con rutinas y procedimientos

7. exhibición de señales de autoridad

8. dificultad en la atención a clientes y conflictos con el público.

A esta relación cabría añadir la Tabla de rangos petrovskiana siempre que no se subsuma a la quinta de las disfunciones, en el sentido de que la excesiva com- 
partimentación de rangos tiene unas consecuencias ontológicas y existenciales tales que anulan al individuo en determinados aspectos en función del rango en que se encuentre.

Alfred Weber, hermano de Max Weber, en su texto Der Beamte (El funcionario), realiza un análisis certero, en el cual se dirige "no a la creciente masa de hombres que se han dejado seducir por el aparato burocrático, sino a aquellos que son capaces de tener planteamientos críticos frente a la gigantesca máquina que se levanta en nuestras vidas. Según sus palabras, el aparato posee la tendencia cada vez mayor a imponerse en sectores libres y naturales, absorbiéndolos en sus aposentos, casilleros y subcasilleros. De él emana el veneno de la esquematización, que ahoga todo lo que le resulta extraño, individual y con vida propia. La burocracia transforma, además, la psicología de la población, convirtiendo a los individuos en buscadores de un puestecillo caliente y cómodo, en arribistas cuya única preocupación es hacer carrera dentro del aparato (...) También Alfred Weber se plantea, como su hermano, el problema de salvar un resto de humanidad, poniendo barreras a un proceso de burocratización que implica la metamorfosis («Verwandlung») de las capas medias y altas de la población en funcionarios y empleados» (González García, 206).

Alfred Weber divide su artículo El funcionario en cinco apartados: en el primero describe una pequeña historia de la burocracia dentro del proceso general de racionalización de la sociedad; en el segundo analiza las ventajas y peligros del proceso de burocratización. Las contrapartidas son muy fuertes: el aparato burocrático exige a cambio obediencia y ataduras de por vida, requiere toda la fuerza de trabajo del individuo. Y, en última instancia, junto con esta fuerza de trabajo, reclama al hombre mismo e incluso su alma. El principal peligro consiste en la identificación con el aparato burocrático, identificación que conduce a confundir el espíritu vacío de la burocracia con el espíritu del tiempo y a unificar vida y trabajo, existencia y profesión. En tercer lugar, Alfred Weber estudia el peligro de la esclavización física y psíquica al aparato burocrático; en cuarto lugar señala Weber que en Alemania, como en todos los países autocrático-burocráticos, el individuo que trabaja para el aparato público deja de ser persona para convertirse en funcionario: ya no significa nada como tal individuo, sino que es tratado sólo por su título, colocado según su posición, estimado según su rango; todas las otras características de su individualidad desaparecen. El último apartado está dedicado a buscar las formas de sal- 
var al individuo como persona, como fuerza viviente, de las garras del aparato burocrático.

Es preciso, para Alfred Weber romper las cadenas exteriores que atan al hombre al aparato burocrático, a los kovaliovs y goliadkines, podríamos decir, a través de cambios institucionales importantes para crear un nuevo derecho administrativo y un nuevo orden constitucional propio del Estado moderno que supere la idea de funcionario como vasallo y lo convierta en ciudadano. Un nuevo orden que otorgue derechos humanos a los funcionarios, les saque de la esclavitud y les devuelva el control sobre sus propias vidas ${ }^{7}$.

Finalmente, nos ocupamos ahora de Descripción de una lucha, una complejísima novela corta escrita alrededor de 1906, justo en los primeros compases del siglo XX, injustamente olvidada a no ser que haya sido condenada a ostracismo por su complejidad. Creo, por tanto, que el problema radica en que o no se la ha entendido o se la ha considerado de manera totalmente injusta como una obra menor. No lo es. De hecho es una de las obras más interesantes de Kafka y representa un auténtico ejercicio hermenéutico de primer orden. Descripción de una lucha es uno de esos texto complejos que abordan de manera radical la cuestión más importante para nosotros: la de nuestra existencia y el camino que debemos decidir tomar alguna vez (en ocasiones más de una vez) en la vida. Como el asunto no es simple, el texto tampoco lo es, pero en este texto no trata de otra cosa que de la realidad. En mi opinión, Kafka está vinculado en este texto a una determinada actitud, modo de pensar y explorar la realidad que no es otro que la fenomenología. El propio Husserl decía: ¡A las cosas mismas!, y en otro lugar decía: «Todo el idealismo alemán me ha producido siempre vómito. Toda mi vida $-\mathrm{y}$ al decirlo sacudía su delgado bastón con un puño de plata e inclinado lo empujaba contra el marco de la puerta - he buscado la realidad» (Fellmann, 86). Explorar la realidad, y más aún el interior del ser humano mismo, sus deseos y perfilar los caminos de su voluntad, no es tarea fácil, pero para Kafka representa un reto, y una lucha, de ahí su Descripción de una lucha.

7 En lo referente a Alfred Weber he estado siguiendo el texto de José M. González García, La máquina burocrática, Madrid, Visor, 1989. 
En el mundo del arte, la fenomenología, es decir, la «ciencia de las esencias» (7), como la define Maurice Merleau Ponty, ha tenido magníficas plasmaciones, tanto en la pintura como en la literatura, entre otras. En la pintura el neolítico y sus figuras esquemáticas de hombrecillos cazando son un ejercicio expresionista en base a una forma rudimentaria de fenomenología de primer orden, donde se prescinde de lo innecesario para ir a la esencia, a la cosa misma (veánse los propios dibujitos que Kafka hacía de corte esquemático y expresionista $\left.{ }^{8}\right)$. El grito, de E. Munch es un ejercicio, en ese mismo sentido, donde no sobra ni falta una pincelada, hay lo justo para representar el grito de soledad, aislamiento y angustia del hombre del siglo XX. La carta a Lord Chandos, de Hugo von Hofmannsthal es una obra profundamente expresionista y fenomenológica, que plantea si es posible realmente una verdadera comunicación, como lo es Descripción de una lucha de Kafka.

La narración de Kafka es como lo puede ser la de otro ser humano en tensión consigo mismo, una tensión que ha de resolverse de un modo u otro y que de no hacerse traerá consigo una carga de frustración como las que hemos podido comprobar a través de las obras de sus antecesores: Dostoievski y Gógol. Su narración, la narración de lo que ocurre en su interior es, por tanto, biográfica, críptica, incomprensible, en gran medida. Descripción de una lucha es una novelita que tras una primera lectura, de llegarse hasta el final, da una sensación no solo de extrañeza, sino también de frustración, de frustración ante un texto en el que apenas se entiende nada de lo que está ocurriendo. La clave: se trata de una variante de Doppelgänger, donde los cuatro personajes de la narración son distintas vertientes del mismo personaje: Kafka (u otra persona ante una tesitura análoga).

El texto está a medio camino entre el Simbolismo y el Expresionismo; es preciso introducirse en él para captar el mensaje oculto, que es el que importa, y no tanto quedarse en el farragoso contenido explícito. $Y$ es preciso ver que el desarrollo de la misma se da en dos planos: uno el de la realidad (dentro de la ficción que es la narración) y otro el de la ensoñación (el sueño despierto propio del Expresionismo, a diferencia del sueño propio del Simbolismo que lo precedió). Esto, ya de entrada, plantea muchos problemas porque de no contemplarse así

\footnotetext{
8 Gandelman, C., «Franz Kafka como dibujante expresionista», en Cuadernos internacionales de historia psicosocial del arte, n. ${ }^{\circ}$ 3, 1983, pp. 45-69.
} 
que es fácil perderse en las primeras páginas. Descripción de una lucha no nos lo pone fácil?.

El problema de fondo que subyace a este texto es, en definitiva, definir qué hacer con la propia vida, es necesario elegir, pero te llaman la atención dos cosas, dos actividades que el autor considera excluyentes: el hedonismo propio del estadio estético kierkegaardiano y la actividad literaria.

En Descripción de una lucha hay, fundamentalmente, cuatro personajes principales:

1. El nuevo conocido (llamémosle NC)

2. El gordo $(\mathrm{G})$

3. El protagonista $(\mathrm{P})$

4. El orante $(\mathrm{O})$

Tengamos ahora en cuenta que, en mi opinión:

a) $\mathrm{NC}=\mathrm{G}$ (representan el estadio estético, el hedonismo, si se quiere) y $\mathrm{P}=\mathrm{O}$ (representan el compromiso con una actividad determinada, excluyente, que es la literatura o la oración)

b) $\mathrm{NC}=\mathrm{G}$ y $\mathrm{P}=\mathrm{O}$ son vertientes de lo mismo: la personalidad de su autor, Kafka (K). Son, por tanto, funciones, más que personajes.

c) Existen dos planos narrativos: el «real» y el de la ensoñación, que guardan un gran paralelismo en lo que acontece. Los acontecimientos que operan en la realidad son análogos a los que operan en la ensoñación. Por ejemplo, $\mathrm{P}$ quiere dedicarse a la literatura, mientras que su homólogo, $\mathrm{O}$, es un orante, pero es que Kafka establece una analogía entre a literatura como forma de plegaria, que es a lo que se dedica $\mathrm{O}$.

d) El Doppelgänger lo representan las identidades en disputa: $\mathrm{NC}=\mathrm{G}$ contra $\mathrm{P}=\mathrm{O}$, quedando victoriosa ésta última identidad que no es otro que el K escritor.

9 En mi artículo «El problema de la comunicación y el concepto de realidad en Descripción de una lucha: el compromiso kafkiano con la literatura», en Sánchez, E., Vanguardias y neovanguardias artísticas, México, Plaza y Valdés, 2003, realizo un estudio más detallado sobre esta obra de Kafka desde un punto de vista más orientado al Expresionismo y la Fenomenología. 
El complejo esquema de la obra es el siguiente:

En este capítulo inicial nos encontramos con el planteamiento general del combate entre la vertiente literaria de Kafka y su vertiente mundana, hedonista. Ambas vertientes quedan plasmadas bajo dos personajes que son en realidad el mismo Kafka (ambas vertientes son de su agrado, pero no pueden, en su modo de entenderlas, convivir). Esos personajes son el protagonista (P), un bebedor solitario, y el nuevo conocido (NC). P es un funcionario insomne, $\mathrm{NC}$ es el joven que se encuentra con Annerl, su novia (aunque parece sentirse atraido por muchas otras mujeres) y va a pasear con P en dirección al monte San Lorenzo, dando la sensación de que el paseo es un trayecto en el que se ha de cumplir algún tipo de misión (tomar una decisión, a la postre). Es preciso plantearse la existencia del NC como una "tendencia a» (la tendencia hedonista del propio Kafka en liza con su tendencia - y compromiso - como escritor: una lucha, en definitiva que ha de ser resuelta. Lo que ocurre en esta novela es que se describe dicha lucha). $\mathrm{P}$ contempla al NC (a su vertiente hedonista) con cariño y hasta se siente orgulloso de su éxito con las mujeres. En la lucha hay un toma y daca de razones y argumentos y no siempre va venciendo el que vencerá al final.

A diferencia de sus ilustres predecesores, Kafka sí resuelve la escisión planteada, de ahí que no comparta, por esta y por numerosísimas otras razones, el carácter sombrío de su obra.

\section{II}

\section{Diversiones o demostración de que es imposible vivir}

\section{Cabalgata}

El combate en este punto es presentado a través de una suerte de ensoñación (propia del expresionismo, frente al sueño, propio del simbolismo) en la que $\mathrm{P}$ cabalga, en su labor poética, es decir, creadora, a lomos de NC. P es dueño y señor de los elementos y en este punto del combate se plantea el por qué de la 
visita del NC, de un enamorado, como si P no tuviera otra cosa que hacer que escuchar a un enamorado parlanchín. Como el NC es, en realidad, P, éste se plantea: «creen estar pasando una velada feliz — refiriéndose al enamoramiento- y ya por eso se alegran de la vida que les espera» (366). Esta reflexión tiene una orientación abiertamente crítica donde la vertiente literaria representada por $\mathrm{P}$ es vista como el camino a seguir. Pero llega un momento en que el NC/ caballo cae, se desploma, herido e inútil, y $\mathrm{P}$ decide continuar su camino...

\section{Paseo}

P decide seguir su camino solo, describe cómo la naturaleza responde a las exigencias de su creador (de él, que maneja el entorno y la belleza que lo circunda a su antojo), la naturaleza que es bella, como bella es la obra de arte, objeto de su pasión por la literatura. Y P afirma: «Encantado con esta visión, me tumbé en el suelo y pensé, mientras me tapaba los oídos para no oír el temido llanto, que allí $^{10}$ podría ser feliz» (368). Este párrafo, el de la creación, es el de la elección de la literatura como forma adecuada de vida para él: «no hace falta mucho valor para vivir aquí» (368).

De repente, en ese combate, le asaltan las dudas: «Oí que alguien sollozaba débilmente a lo lejos» (368). La descripción de la naturaleza en este momento se torna más sombría, como si de una regresión en el camino se tratara. La duda (y el combate) queda plasmado en la siguiente afirmación: «Me disponía a dar media vuelta para abandonar aquél paraje y regresar a mi forma de vida anterior» (369).

\section{El gordo}

\section{a. Alocución al paisaje}

Mientras esto sucedía, una persona extremadamente gorda atraviesa un río en un palanquín de madera.

${ }^{10}$ En la literatura, en la belleza, en mi interpretación. 
El gordo, que es una nueva re-presentación de NC, que recordemos era mundano y enamoradizo, dice: «El paisaje — que le encanta a $\mathrm{P}$ — no me deja pensar con claridad (...) hace que mis reflexiones vacilen como puentes colgantes sobre un torrente furioso» (369). El gordo también se ve atraído por el paisaje (al fin y al cabo el amor mundano puede ser tan lírico como el paisaje), pero finalmente se ve agobiado por él y le dice al paisaje: «dejadme un poco de espacio para poder respirar» (370). Pero los porteadores se van hundiendo al pasar a este personaje extremadamente gordo por el río... El gordo se hunde... «Volví a trepar velozmente por el talud, dice $\mathrm{P}$, a fin de acompañar al gordo desde el camino, pues sentía por él (es decir, por sí mismo en su vertiente amorosa y mundana) ${ }^{11}$ verdadero aprecio» (371). El gordo le dice a P que no intente salvarlo, que está perdido, y alude a su amigo el orante $(\mathrm{O})$. Y el gordo sigue contando...

\section{b. Inicio de la conversación con el orante}

... o la literatura como plegaria.

El gordo le comenta a P cómo conoció al orante (que es el otro yo de P, uno reza, el otro escribe). Hubo un tiempo en que el gordo (que es el equivalente al NC) iba a la iglesia pues se había enamorado de una chica. Siempre lo mismo: el gordo enamorado, el NC enamorado. Un día la chica no apareció por la iglesia y le llamó al gordo la atención un joven que oraba y que por su forma de orar llamaba la atención. El gordo quiso abordarlo para pedirle explicaciones de por qué oraba de esa manera, con aspavientos (en realidad, mucho escritores, de la misma manera que muchos fieles que en la oración se golpean el pecho y llaman la atención por la forma de sus rezos, manifiestan sin ambajes su vanidad a través de prácticas no exentas de un cierto espectáculo y provocación). Finalmente lo consigue. Lo aborda, le pide explicaciones. El orante afirma que «la finalidad de sus rezos es que la gente le mire», como cualquier otro literato (o artista) quiere que lo lean, que lo admiren. La debilidad sublimada se convierte en un mecanismo magnífico como salida airosa a problemas de diferente índole. El gordo le sigue recriminando la forma de actividad. Todo esto forma parte del combate.

11 Las aclaraciones entre paréntesis son mías. 
El orante, no obstante, proclama sus dudas e inquietudes: «nunca ha habido un momento en el que estuviera convencido de mi vida por mí mismo» (377), y explica qué espera de su actividad (la oración o, en su caso, la literatura) de una manera abiertamente fenomenológica: «siempre, querido señor, me entran unas ganas atroces de ver las cosas tal y como se presentarían antes de mostrárseme. Sin duda están ahí, hermosas y tranquilas» (377). El orante comienza a decantar la balanza en el combate a su favor.

Es importante, valga el inciso, hacer notar que en Kafka, la utilización de ciertos recursos como la fantasía en La transformación o este peculiar mecanismo que es el Doppelgänger en una versión muy personal tiene un objetivo claro, probablemente, muy distinto al que tuvieron originalmente ambos mecanismos en obras precedentes. El objetivo no es simplemente impresionar al lector con fórmulas tan provocadoras y sugerentes, sino bucear en lo más profundo de la realidad con estos utensilios. El efectismo de estos mecanismos en Kafka huye de la espectacularidad que en otros momentos, tanto precedentes como posteriores, han tenido. El Doppelgänger es un mecanismo que se presta perfectamente al efecto psicológico del terror. En Kafka hay una inquetante «normalidad» a pesar de la forma que adopta la narración.

\section{c. Historia del orante}

Ahora el orante se sumerge en un ambiente festivo; es necesario conocer lo que denostas o el camino que no piensas seguir. Allí entabla conversación con una señorita que no está de acuerdo con él y que lo acusa de no tener tratos con la verdad porque, según ella, la verdad es demasiado agotadora. El orante le dice que de entre toda la gente superficial de la fiesta, ella lo está atacando a él, pero centrándose en su persona, pues no puede hacer más... Llega un momento en que ella ya no está junto a él, ha decidido compartir esos momentos con tres banales jóvenes... Parece que esta actitud de ella y sus compañías le han hecho decidir qué camino llevar, e incluso afirma: «estoy a punto de ser feliz. Se trata de un triunfo» (382). Finalmente es, cortésmente, invitado a abandonar la fiesta.

\section{d. Prosigue la conversación entre el gordo y el orante}

El gordo le dice: «ya va siendo hora de que hables. Estás muy confuso» (387). 
Y prosigue una pregunta fundamental por parte de G: «¿No se podría vivir de otro modo?». «No, dijo él sonriente e interrogativo». «Pero ¿por qué reza usted de noche en la iglesia? (recordemos que era costumbre del insomne Kafka escribir en la noche), pregunta el gordo, mientras entre ambos se derrumbaba todo lo que hasta entonces había el gordo apuntalado como en sueños» (388). El combate va avanzando y el orante está venciendo. Esto queda claramente plasmado en:

Orante: 1. «Quizá sea conveniente ir a la iglesia y rezar a gritos para ser observado y acabar teniendo un cuerpo» (388).

Gordo: 2. «Como habló así y luego se calló, yo saqué mi pañuelo rojo del bolsillo y rompí a llorar, encorvado» (388).

El combate se va decantando claramente a favor del orante: «Mi amigo caminaba con dificultad» (389).

\section{Final del gordo}

Aquí prosigue cronológicamente la conversación de $\mathrm{P}$ con el gordo cuando éste le decía a P que no intentara salvarlo, que está perdido, y aludía a su amigo, el orante... Al gordo se lo lleva la corriente y cae por una catarata. El desenlace no podía ser otro; el orante, que ha determinado el curso de su vida, es el verdadero responsable de su ahogamiento.

Ha finalizado una parte del combate: el combate entre el orante y el gordo. Queda por resolver el combate entre P y NC. Claro está que si nuestra hipótesis está fundamentada sobre estas identidades $(\mathrm{P}=\mathrm{O}$ y $\mathrm{NC}=\mathrm{G})$ y el gordo ha muerto, el combate se resolverá a favor de P. Habrá pues triunfado la oración, la plegaria, la literatura (que Kafka consideraría como forma de plegaria) como compromiso y habría sucumbido el amor carnal que se interpone entre Kafka y la literatura como pasión exclusiva, imposible de compatibilizar con cualquier otra actividad.

P sigue en su ensoñación y se hace omnipotente... pero pronto cae en la cuenta de que debe de ser cauto y que deben ser los demás los que deben de juzgarlo (como literato) y decir hasta dónde debe de llegar: «Pero no, no es esto...yo 
soy pequeño, por ahora pequeño... voy rodando... rodando... ¡soy un alud en la montaña! Por favor, vosotros que pasáis por aquí, decidme cuán alto soy, medid estos brazos, estas piernas!» (390-391)».

\section{III}

$\mathrm{Y}$, finalmente, prosigue $\mathrm{P}$ (ya fuera de la ensoñación) junto con NC su paseo al monte San Lorenzo. P manifiesta que sí, que la enamorada de NC es bella (aunque él prefiere otra belleza, la literaria) y afirma en un párrafo muy revelador la caducidad de esa belleza efímera:

"iLa belleza de las muchachas en general! A menudo, cuando veo vestidos con múltiples pliegues, volantes drapeados que ciñen bellamente cuerpos bellos, pienso que no se mantendrán así mucho tiempo, sino que les saldrán arrugas imposibles de alisar, que el polvo los cubrirá, espesándose en los ornamentos, y ya no habrá cómo quitarlo, y que nadie querrá dar una impresión tan triste y ridícula poniéndose cada mañana el mismo lujoso vestido y quitándoselo por la tarde. Y, no obstante, veo muchachas que sin duda son bonitas y muestran atractivos músculos y huesecillos, y una piel tersa y matas de finos cabellos, y, sin embargo, se presentan cada día con esa especie de disfraz natural, apoyan siempre el mismo rostro en la misma palma de la mano y dejan que su espejo lo refleje. Solo a veces, ya de noche, cundo vuelven tarde de alguna fiesta, les parece en el espejo consumido, hinchado, cubierto de polvo, visto ya por todos y apenas llevadero» (392).

$\mathrm{NC}$ es ridiculizado como amante en tanto alberga dudas sobre si es fiel y leal, inclusive desconoce en qué se pueda estar metiendo si se compromete con una mujer. El problema, pues, no es que a Kafka no le interese el amor, es que no tiene claro que el amor que él puede sentir por una mujer tenga demasiado sentido: «En esto no hay nada seguro». «Tendrá que darse muerte!» (393), le insta $\mathrm{P}$ a NC, dadas las dudas que tiene sobre esa forma hedonista de vida, carente de compromiso que representa. No pueden sobrevivir ambas vertientes: una ha de fenecer. El camino queda allanado para la victoria de P, el protagonista, la vetiente literaria de Kafka. En ese momento «y sin más preámbulos, mi conocido se sacó una navaja del bolsillo, la abrió con aire pensativo y se la clavó como jugando en el brazo izquierdo, sin sacársela. Al instante brotó sangre» (394-395). 
Esta variante kafkiana de Doppelgänger, del «que camina al lado» cumple, al mismo tiempo tanto con la característica de la bilocación como con la más sombría de las espectativas: la nefasta consecuencia de uno de los referentes; en este caso la muerte tanto del gordo como del nuevo conocido, situados ambos en la que Kierkegaard denominara etapa estética para encarnado en el protagonista, tomar otro derrotero más cercano a la concepción ética también kierkegaardiana, la del compromiso, el compromiso de Kafka con la literatura, un compromiso exclusivo.

\section{Bibliografía}

Dostoievski, F. M. (1996). El doble, Madrid, Alianza.

EyMAR, C. (1995). El funcionario poeta, Madrid, Tecnos.

Fellman, F. (1984). Fenomenología y expresionismo, Barcelona, Alba.

Gandelman, C. (1983). «Franz Kafka como dibujante expresionista», en Cuadernos internacionales de historia psicosocial del arte, $\mathrm{n} .{ }^{\circ} 3$.

Gógol, N. (1998). «La nariz», en Historias de San Petersburgo, Madrid, Alianza.

GonZÁlez GarCía, J. M., La máquina burocrática, Madrid, Visor, 1989.

Horney, K. (1959). El nuevo psicoanálisis, México, Fondo de cultura económica.

- (1959). Neurosis y desarrollo humano. Buenos Aires, Psique.

KAFKA, F. (2003). «Descripción de una lucha», en Obras Completas III, Barcelona, Galaxia Gutenberg.

LA RuBiA, L., coord. (2003). «La locura en los cuentos de Gógol. Funcionarios artistas e identidad», en Gógol y su legado, México, Plaza y Valdés.

- (2003). «El problema de la comunicación y el concepto de realidad en Descripción de una lucha: el compromiso kafkiano con la literatura», en Sánchez, E., Vanguardias y neovanguardias artísticas, México, Plaza y Valdés.

MartíneZ, I. (2003). Dostoievski: de la igualdad a la diferencia, Madrid, Biblioteca Nueva.

Merleau-Ponty, M. (1985). Fenomenología de la percepción, Barcelona, Planeta-Agostini.

Newberry, W. (1977). The Pirandellian Mode in Spanish Literature from Cervantes to Sastre, New York, State University of New York Press. 
- (1984). «Ramón Pérez de Ayala’s Concept of the Doppelgänger in Belarmino y Apolonio".

Siebers, T. (1984). Lo fantástico romántico, México, FCE.

SCHUlZ, B. (1998). Obras completas, Madrid, Siruela.

Unamuno, M. (1998). El otro, Madrid, Espasa Calpe.

Weber, A. (1979). «Der Beamte», en Haben wir Deutschen nach 1945 versagt?, München, Piper.

Recibido: 4/10/2009

Aceptado: 31/07/2010 